\title{
Alpin kayalık habitatlardaki doğal bitki taksonlarının bitkisel tasarımlardaki fonksiyonları bakımından değerlendirilmesi
}

\section{Evaluation of the natural plant taxa in alpine rocky habitats in terms of the functions of planting design}

Derya SARI ${ }^{1}$, Cengiz ACAR ${ }^{2}$

${ }^{1}$ Artvin Çoruh Üniversitesi Orman Fakültesi Peyzaj Mimarlığı Bölümü

2Karadeniz Teknik Üniversitesi Orman Fakültesi Peyzaj Mimarlığı Bölümü

\section{Özet}

Biyoçeşitlilik açısından değerli ve hassas ekosistemleri barındıran alpin alanlar, sahip oldukları farklı habitatlarlar ile doğal peyzajın eşsiz öğelerini oluşturmaktadırlar. Bunlardan biri de kayalık habitatlardır. Alpin ve kayalık habitatlarda yaşayan birçok bitki türü, özellikle estetik özellikleriyle dikkat çekmiş ve zaman içerisinde insanların talepleri doğrultusunda bitkisel tasarımlara katılmaya başlamıştır. Bu çalışmada, kayalık habitatların çeşitli ve farklı ölçeklerde izlenebildiği, aynı zamanda da sahip olduğu zengin floristik çeşitlilik bakımından dikkat çekici olan Hatila Vadisi Milli Parkı (Artvin)'nda belirlenen 12 adet alpin kayalık alan incelenmiştir. Arazi çalışmaları sonucunda örnek kayalık alanlarda, 40 familyaya ait, 12'si endemik olmak üzere toplam 187 bitki taksonu tespit edilmiştir. Taksonların tür kompozisyonları ise kümeleme analizi ile belirlenmiştir. Çalışma kapsamında, örnek alanlarda tespit edilen doğal taksonların çeşitli morfolojik ve estetik özellikleri (renk, doku, form, yaşam formu) bakımından sınıflandırması yapılarak, süs bitkisi olarak değerlendirilebilecek bazı taksonlar ve bunların bitkisel kompozisyonlardaki fonksiyonlarına (yapısal, odakvurgu, dolgu-destek) yönelik bir öneri tablosu geliştirilmiştir.

Anahtar kelimeler: Alpin kayalık habitatlar, Alpin bitkiler, bitkisel tasarım, doğal bitki kompozisyonu, Hatila Vadisi Milli Parkı

\section{Abstract}

Alpine areas that have valuable and sensitive ecosystem in terms of biodiversity are the unique elements of the natural landscape with different habitats. One of them is the rocky habitats. Many plant species living in alpine and rocky habitats, especially their attention to aesthetic properties has begun to take place in planting design with demands of the people in the course of time. In this study, 12 alpine rocky areas were examined in Hatila Valley National Park (Artvin) that can be viewed at different scales and various rocky habitats also have the striking rich floristic diversity. As a result of field work, 187 plant taxa, 12 of which are endemic, with $\mathbf{4 0}$ families identified in sample rocky areas. Species composition of taxa was identified by the cluster analysis. In this context, native taxa identified in sample areas were classificated according to morphological and aesthetic characteristics (color, texture, form, life form). Some taxa which can be used as an ornamental plant, and their function (structural, focus-emphasis, fill-support) in the plant composition was presented with a suggestion table.

Keywords: Alpine rocky habitats, Alpine plants, Hatila valley national park, natural plant composition, planting design 


\section{GiRiş}

Biyoçeşitlilik açısından değerli ve hassas ekosistemleri barındıran alpin alanlar, aynı zamanda sahip oldukları farklı habitatlarlar ile doğal peyzajın eşsiz elemanlarından birini oluşturmaktadırlar. Alpin ekosistemlerdeki biyoçeşitlilik, insan aktivitelerinin yaygın baskısı nedeniyle günümüzde büyük bir tehdit altındadır, örneğin karbondioksit artışıyla birlikte gelişen küresel ısınma, alpin türlerin yüksek kesimlere göç etmesine neden olmaktadır. Bu durum, ileriki yıllarda taksonların gittikçe daralan alpin zonlarda ve dağların yüksek kesimlerinde kendilerine yaşama alanı bulmaya çalışacakları sunucunu doğurmaktadır (Körner 1995). Öte yandan, dağlık alanlarda sosyal ve kültürel faaliyetlerin hiç ya da çok sınırlı düzeyde olması, bu alanlarda yetişen bitkilerin diğer alanlarda yetişen bitkilere göre daha az deformasyona uğramasını sağlamaktadır (Good 1992).

Alpin ve dağlık alanlarda biyoçeşitlilik ve floristik çeşitlilik açısından dikkat çeken habitatlardan biri de kayalık habitatlardır. Bu alanlarda, jeoloji, yükseklik, iklim ve konum nedeniyle gelişen koşullara göre her biri benzersiz olan kayalıklar ortaya çıkmaktadır. Kayalık alanlar genellikle çok eğimli, yüzeysel akışın hızlı olduğu, erozyon gibi çevresel baskıların hissedildiği, mikro ölçekte bakı farklılıklarına sahip özel habitatlardır. Bu nedenle kayalık habitatlar izole kalmış birçok bitki ve hayvan topluluklarına ev sahipliği yapmaktadır. Nitekim alpin alanlar ve kayalık habitatlarda yaşayan birçok bitki türü özellikle estetik özellikleri ile insanların dikkatini çekmektedir. Bu nedenle, birçok alpin bitkisi zaman içerisinde insanların talepleri doğrultusunda peyzaj çalışmalarında yer bulmaya ve bitkisel tasarımlara katılmaya başlamıştır.

Alpin alanlarda ve kayalık habitatlarda bulunan bitki türlerinin tespiti ve kültüre alınarak süs bitkisi olarak bitkilendirme tasarımlarında kullanılmaya başlanması 20. yy.'ın başlarında görülmektedir. Günümüzde birçok ülkede doğal bitki türlerinin korunması, araştırılması ve kullanımının yaygınlaştırılması ile ilgili çalışmalar yapan kuruluşlar bulunmaktadır, bunlardan biri Alpin Bahçe Topluluğu (Alpine Garden Society)'dur. Bunun yanısıra konu ile ilgili uluslararası sempozyumlarda da bitkilerin korunmasının; Tarihi önem, Genetik önem, Estetik ve bahçe kalitesi/değeri, İnsana fayda/ kullanışlılık, Bahçelerdeki yabani bitkilerin korunması, Doğal koleksiyonlar, Nadir ve tehdit altındaki türlerin korunması bakımından önemli olduğu kaydedilmiştir (Evans 1981). Ülkemizde ise 'Vizyon 2023' kapsamında, biyolojik çeşitliliğin korunması ve sürdürülebilir kalkınma kapsamında belirlenen uygulama mekanizmalarından biri olan "Yerli türlerin geliştirilmesi ve daha yaygın olarak kullanımının sağlanması konusunda çalışmalar yapılmalıdır" (TUBITAK 2002) maddesi kabul gören hususlardan biridir.

Ülkemiz, coğrafi konumu nedeniyle biyoçeşitliliğe çok önemli katkıda bulunan alpin ve dağlık alanlar bakımından zengin sayılmaktadır. Örneğin Türkiye'nin 144 Önemli Bitki Alanından 60 tanesi (yaklaşık \%42'si) dağlık alanlardır (Atay ve ark. 2009). $\mathrm{Bu}$ bağlamda alpin ve kayalık habitatlarımızda, peyzaj çalışmalarına kazandırabileceğimiz birçok doğal bitki 
türünden bahsetmek mümkün olabilmektedir. Son zamanlarda kentsel açık yeşil alanlarda (kamusal, yarı kamusal ve özel alanları içeren) egzotik bitkilerin gün geçtikçe artarak kullanıldığını ortaya koyan bazı çalışmalar (Kowarik 1995; Thompson ve ark. 2003; Turner ve ark. 2005; Acar ve ark. 2007; Acar ve Sarı 2010) göz önüne alındığında, doğal kaynaklarımızı daha doğru kullanmak ve tür çeşitliliği bakımından giderek aynılaşan kentlerimizde, doğal bitki türlerimizin bitkisel tasarımlarda kullanılabilmesi üzerine çalışmalar önem kazanmalıdır.

Dolayısıyla bu çalışma kapsamında, alpin kayalık habitatlardaki doğal bitki taksonlarının belirlenmesi ve buradan hareketle peyzaj çalışmalarında kullanılabilecek bitki taksonlarının ve bu taksonların bitkisel tasarımlarda hangi fonksiyonları bakımından kullanılabileceğine ilişkin bir değerlendirme sunulmaktadır. Çalışma kapsamında, kayalık habitatların çeşitli ve farklı ölçeklerde izlenebildiği, aynı zamanda da sahip olduğu zengin floristik çeşitlilik bakımından dikkat çekici olan Hatila Vadisi Milli Parkı (HVMP) örnek çalışma alanı olarak seçilmiştir. HVMP'nda belirlenen12 adet alpin kayalık alanda çalışma yürütülmüştür. Örnek alanlarda tespit edilen bitki taksonlarının tür kompozisyonları kümeleme analizi ile belirlenmiş ve taksonların çeşitli morfolojik ve estetik özellikleri doğrultusunda sınıflandırması yapılarak bitkisel tasarımlarda kullanılabileceği fonksiyonlarına yönelik bir öneri tablosu geliştirilmiştir.

\section{Materyal ve Yöntem}

\section{Çalışma alanı}

Çalışma alanı olan HVMP, Artvin ili, merkez ilçe sınırları içerisinde, konum olarak $41^{\circ} 10^{\prime} 00.66^{\prime \prime}$ kuzey enlemi - 414'11.19" doğu boylamı koordinatlarında yer almaktadır. (Anonim, 2014) (Şekil 1). Artvin ilinin $30 \mathrm{~km}$ batısında yer alan Hatila Vadisi, 1994 tarihinde Milli Park ilan edilmiştir. HVMP'nın toplam alanı 16988 ha olup alanın en yüksek noktasının rakımı 3224 m (Kurt Dağı), en düşük noktasını rakımı 160 m (Çoruh Nehri)' dir (Anonim 2005). HVMP, bitki coğrafyası ve flora bölgeleri açısından Holartik Flora bölgesinin Euro - Siberian flora alanının kolşik kesimi içinde kalmaktadır (Anşin ve ark. 2000). Alan, Davis'in kare sistemine göre ise A8 karesinde yer almaktadır (Davis 1965-1988). HVMP'nın yer aldığı "Kafkasya Ekolojik Bölgesi" uluslar arası çevre koruma örgütü, Dünya Bankası ve GEF (Küresel Çevre Fonu) tarafından dünyanın biyolojik çeşitlilik açısından en zengin ve aynı zamanda tehlike altındaki en önemli 25 karasal ekolojik bölgesinden biri olarak tanımlanmaktadır (Karaer ve Terzioğlu 2012). HVMP içerisinde kayalık alan ekosistemi, 1045 ha.'lık bir alan kaplamaktadır. Bu alandaki kayalık vejetasyon ise 221 ha.'lık bir alana sahiptir. HVMP'nde floristik olarak, 109 familyaya ait 1349 takson bulunduğu ve bunlardan 12'sinin Artvin endemiği olmak üzere toplam 125 taksonun endemik olduğu tespit edilmiştir (Karaer ve Terzioğlu 2012). 


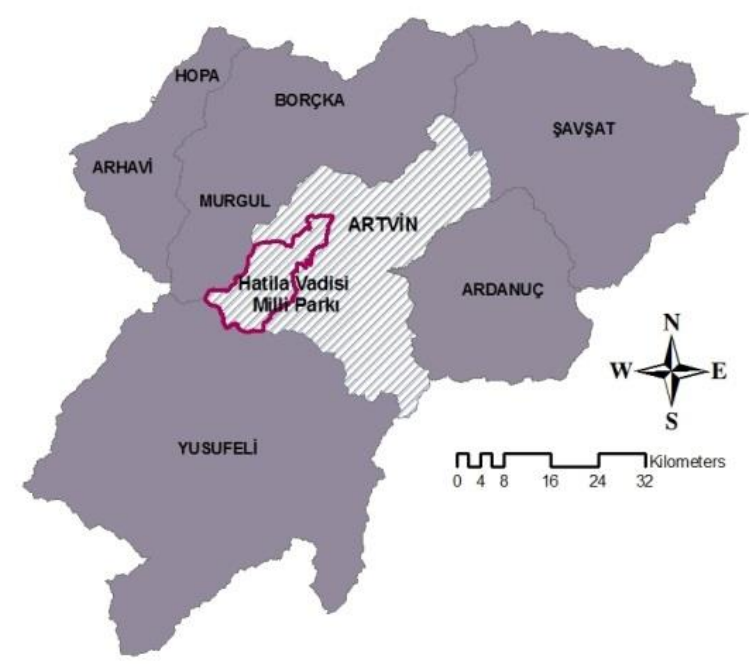

Şekil1. Çalışma alanı, Hatila Vadisi Milli Parkı, Artvin.

\section{Örnek alanlar}

Çalışmada, HVMP Alpin kesiminde, 2350$2720 \mathrm{~m}$ arası yükseltilerde yer alan kayalık habitatlarda belirlenen 12 örnek kayalık alanın arazi çalışmaları ile floristik ve konumsal verileri elde edilmiştir. Araştırılan bölgede kayalık alanlar homojen bir yapı sergilemediğinden kayalık alan örnekleri bilinçli rastgele örnekleme yöntemine göre seçilmiştir (Akman ve ark. 2011) (Şekil 2 ve 3). HVMP alpin kesimdeki örnek kayalık alanlar daimi örneklik alan olarak belirlenmiştir.
Çalışma alanlarındaki bitki materyali tespit edilirken örneklik alan büyüklügüu, alan - tür ilişkisine göre ortaya çıkan "en küçük alan" yöntemine göre belirlenmiştir. Dolayısıyla örnek kayalık alan büyüklüğü de buna göre belirlenmiştir. Floristik verilerinin elde edilmesinde Braun - Blanquet yönteminden faydalanılmıştır (Acar 1997; Terzioğlu 1998; Terzioğlu ve ark. 2007; Akman ve ark. 2011). Buna göre her bir örnek alanda bitki türlerinin bulunma durumu tespit edilmiştir.

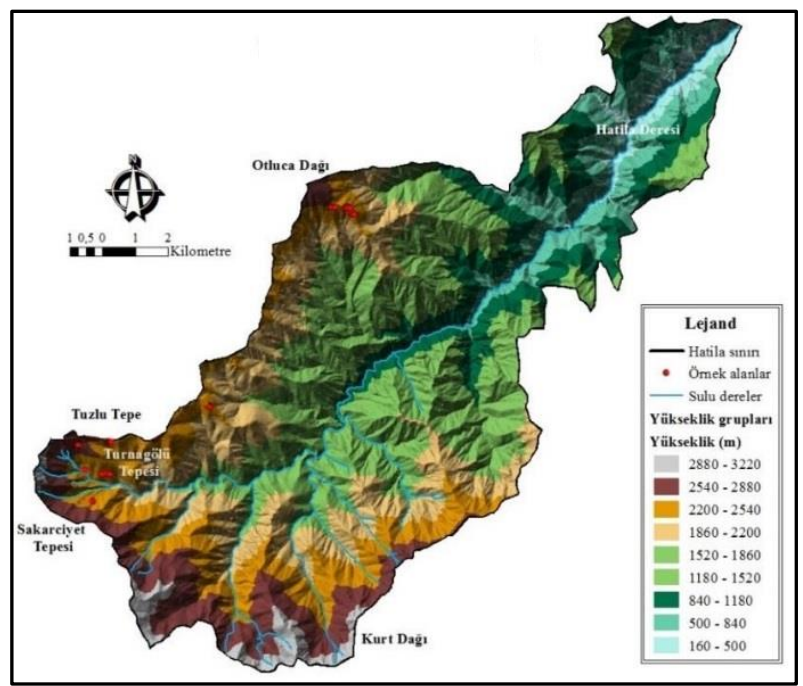

Şekil 2. Örnek kayalık alanların HVMP üzerindeki konumu 

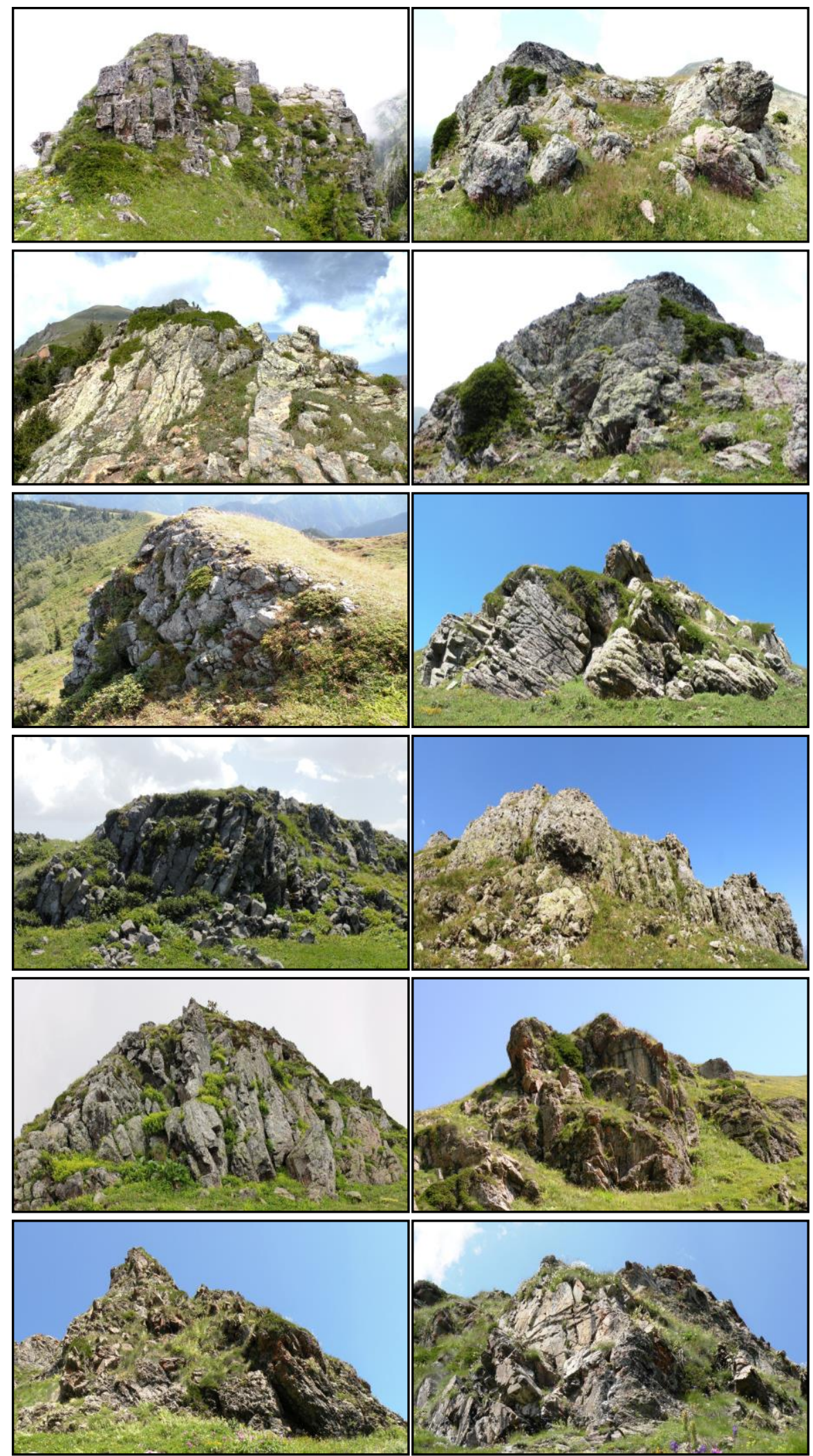

Şekil 3. Örnek kayalık alanlara ait fotoğraflar 


\section{Verilerin değerlendirilmesi}

Örnek alanlardan toplanan bitki örneklerinin teşhis aşamasında, "Flora of Turkey and East Aegean Islands" (Davis 1965-1988) eserinden yararlanılmıştır. Bitki verileri bilgisayar ortamına aktarılırken bitki türünün; Familyası, Tür adı, Hayat formu, Çiçek rengi, Yaprak rengi, Dokusu (ince-gevşek, orta, sıkkaba dokulu), Formu/habitusu (dik form, eğik tırmanışlı, yatık gövdeli, sürünücü, yayılıcı, bodur tümsek, küme, yastık, yumak, rozet, mozaik-yosun, rizomlu-stolonlu), Endemiklik, Herbaryum numarası ve Toplayıcı numarası gibi bilgilerin girildiği Excel tabloları oluşturulmuştur. Tüm taksonların bu özelliklere göre hazırlanan özet tablosu Ek tablo'da sunulmuştur. Bitkilerin bazı estetik ve morfolojik özelliklerinin değerlendirilmesi aşamasında; renk (çiçek, yaprak, meyve rengi) (Booth 1990), doku (Booth 1990; Karaşah 2006), form tipleri (Acar 1997) ve yaşam formu (Davis 1965-1988) özellikleri ele alınmıştır.

Bitki taksonlarının örnek alanlardaki dağıımı (bulunup bulunmama) dikkate alınarak taksonların oluşturuduğu kompozisyonların belirlenmesinde, türler veya örnek alanlar arasındaki benzerlik indeks değerlerinden yararlanarak vejetasyonun sınıflandırılmasında kullanılan ve bir küme analizi (Cluster Analysis) tekniği olan Neighbour joining kümeleme yöntemi kullanılmıştır. Taksonların dendogramı oluşturulurken Gower benzerlik indeks aralığı tercih edilmiştir. Bitki kompozisyonları analizlerinde PAST 3. 1 veri analizi programından (Palaeontological Statistics) faydalanılmıştır.

\section{BULGULAR VE TARTIŞMA}

HVMP alpin kayalık habitatlarında belirlenen 12 örnek alanın mevki, yükseklik, bakı, yüzey eğimi ve örnek alan büyüklüğü verileri Çizelge 1 'de verilmiştir. Buna göre örnek alanların bulunduğu yükseklik en az $2350 \mathrm{~m}$, en fazla 2720 m'dir. Örnek alanların 8 tanesi gölgeli bakıda, 4 tanesi güneşli bakıda bulunmaktadır, yüzey eğimi ise ortalama $51^{\circ \prime}$ dir. Örnek kayalık alanların büyüklüğü oratalama $46 \mathrm{~m}^{2}$ dir.

Çizelge 1. Örnek kayalık alanların konumsal özellikleri

\begin{tabular}{llllll}
\hline $\begin{array}{l}\text { Örnek alan } \\
\text { no }\end{array}$ & Mevkii & $\begin{array}{l}\text { Yükseklik } \\
(\mathbf{m})\end{array}$ & Bakı & Eğim () & $\begin{array}{l}\text { Örnek alan } \\
\text { büyüklüğü }\left(\mathbf{m}^{\mathbf{2}}\right)\end{array}$ \\
\hline 1 & Otluca Dağı, Gölehura Yaylası & 2370 & Kuzey & 80 & 48 \\
2 & Otluca Dağı, Gölehura Yaylası & 2475 & Güneydoğu & 30 & 50 \\
3 & Otluca Dağı, Gölehura Yaylası & 2458 & Doğu & 50 & 50 \\
4 & Otluca Dağı, Gölehura Yaylası & 2450 & Kuzeydoğu & 75 & 60 \\
5 & Tuzlu Tepe, Danayayımı Yaylası & 2358 & Doğu & 80 & 40 \\
6 & Sakarciyet Tepesi, Danzotlu Yaylası & 2362 & Kuzey & 40 & 60 \\
7 & Sakarciyet Tepesi, Danzotlu Yaylası & 2520 & Güney & 30 & 40 \\
8 & Sakarciyet Tepesi, Danzotlu Yaylası & 2630 & Kuzey & 70 & 50 \\
9 & Turnagölü Tepesi, Danzotlu Yaylası & 2720 & Güneybatı & 35 & 40 \\
10 & Sakarciyet Tepesi, Danzotlu Yaylası & 2370 & Kuzeybatı & 45 & 50 \\
11 & Sakarciyet Tepesi, Danzotlu Yaylası & 2445 & Güneydoğu & 45 & 30 \\
12 & Sakarciyet Tepesi, Danzotlu Yaylası & 2350 & Kuzeybatı & 35 & 30 \\
\hline
\end{tabular}




\section{Taksonların Dağılımı ve Genel Kompozisyonları}

Arazi çalışmaları ile elde edilen veriler sonucunda örnek kayalık alanlarda, 40 familyaya ait 187 bitki taksonu tespit edilmiş, bunlardan 12 taksonun endemik olduğu belirlenmiştir (Ek Tablo). Bitki taksonlarının familyalara göre dağılımları ise şu şekildedir: Asteraceae / Compositae (28), Rosaceae (24), Gramineceae /Poaceae Caryophyllaceae (9), Crassulaceae (8), Apiaceae / Umbelliferae (7), Lamiaceae / Labiatae (7), Leguminosae / Fabaceae (7), Scrophulariaceae (7), Campanulaceae (6), Liliaceae (5), Aspleniaceae (4) Boraginaceae (4), Dipsacaceae (4), Geraniaceae (4), Hypericaceae/ Guttiferae (4), Primulaceae (4), Ericaceae (3), Gentianaceae (3), Ranunculaceae (3), Saxifragaceae (3), Aspidiaceae (2), Brassicaceae / Cruciferae (2), Cupressaceae (2), Orchidaceae (2), Pinaceae (2), Polygalaceae (2), Polygonaceae (2), Rubiaceae (2), Valerianaceae / Caprifoliaceae (2), Violaceae (2), Cistaceae (1), Cyperaceae (1), Empetraceae (1), Euphorbiaceae (1), Iridaceae (1), Juncaceae (1), Onagraceae (1), Rhamnaceae (1), Thymelaeaceae (1). Bitki taksonlarının örnek alanlara göre dağılımlarına bakıldığında en fazla takson sayısının 10. örnek alanda (163 takson), en az takson sayısının 5. örnek alanda (94 takson) bulunduğu görülmektedir (Şekil 4). Çalışma alanlarında tespit edilen endemik taksonlar, Anthemis melanoloma, Hieracium insolitum, Hieracium karagoellense, Gypsophila simulatrix, Sempervivum minus, Sempervivum ekimii, Geranium cinereum subsp. subcaulescens var. lazicum, Festuca amethystina subsp. orientalis var. turcica, Helictotrichon pubescens subsp. pubescens, Allium djimilense, Muscari coeleste, Potentilla doddsii'dir.

Örnek alanlarda tespit edilen taksonların bulunma/bulunmama durumlarına göre oluşturuduğu kompoziyonlara bakıldığında, bulunma oranı $\% 40$ ve üzeri olan taksonların küme analizi sonucunda 4 ana grubun oluştuğu görülmektedir (Şekil 5). Buna göre 62 takson tüm örnek alanlarda bulunmakta olup 1. grupta, 37 takson 2. grupta, 20 takson 3. grupta ve 27 takson 4. grupta kümelenmektedir.

Kayalık habitatların ekolojik özellikleri bu alandaki vejetasyon yapısını ve bitki çeşitliliğini etkileyen en önemli belirleyici olmaktadır. Taksonların oluşturduğu kompozisyonlara bakıldığında, genel dağılımda çok yıllık çiçekli otsu bitki türlerinin ağırlıklı olduğu görülmüştür. Özellikle kayalık habitatlardaki özel yetişme ortamı özellikleri floristik çeşitliliği, tür kompozisyonlarını ve endemikliği olumlu yönde etkilemektedir. Farklı kayalık yapıları kendine has farklı bitki topluluklarıyla bütünlük oluşturmaktadırlar (Main, 1997). Kayalıklar üzerindeki takson sayısı, bitki türlerinin yaşayabileceği nişlerin büyüklüğüne bağlı olarak değişebilmektedir. Mikrotopografik özellikler, (kaya çatlakları, oyuklar ve yarıklar gibi), mikroklima yaratan abiyotik faktörler ile birleşerek kayalık alanlardaki bitki türlerinin ve dolayısıyla da biyoçeşitliliğinin dağılımını etkilemektedir (Coates ve Kirkpatrick 1992). 


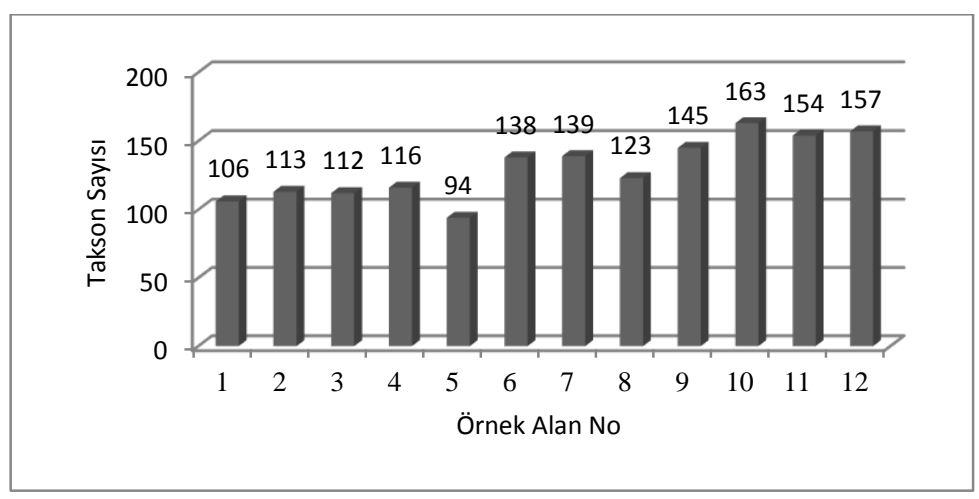

Sekil 4. Bitki taksonlarının örnek alanlara göre dağılımları

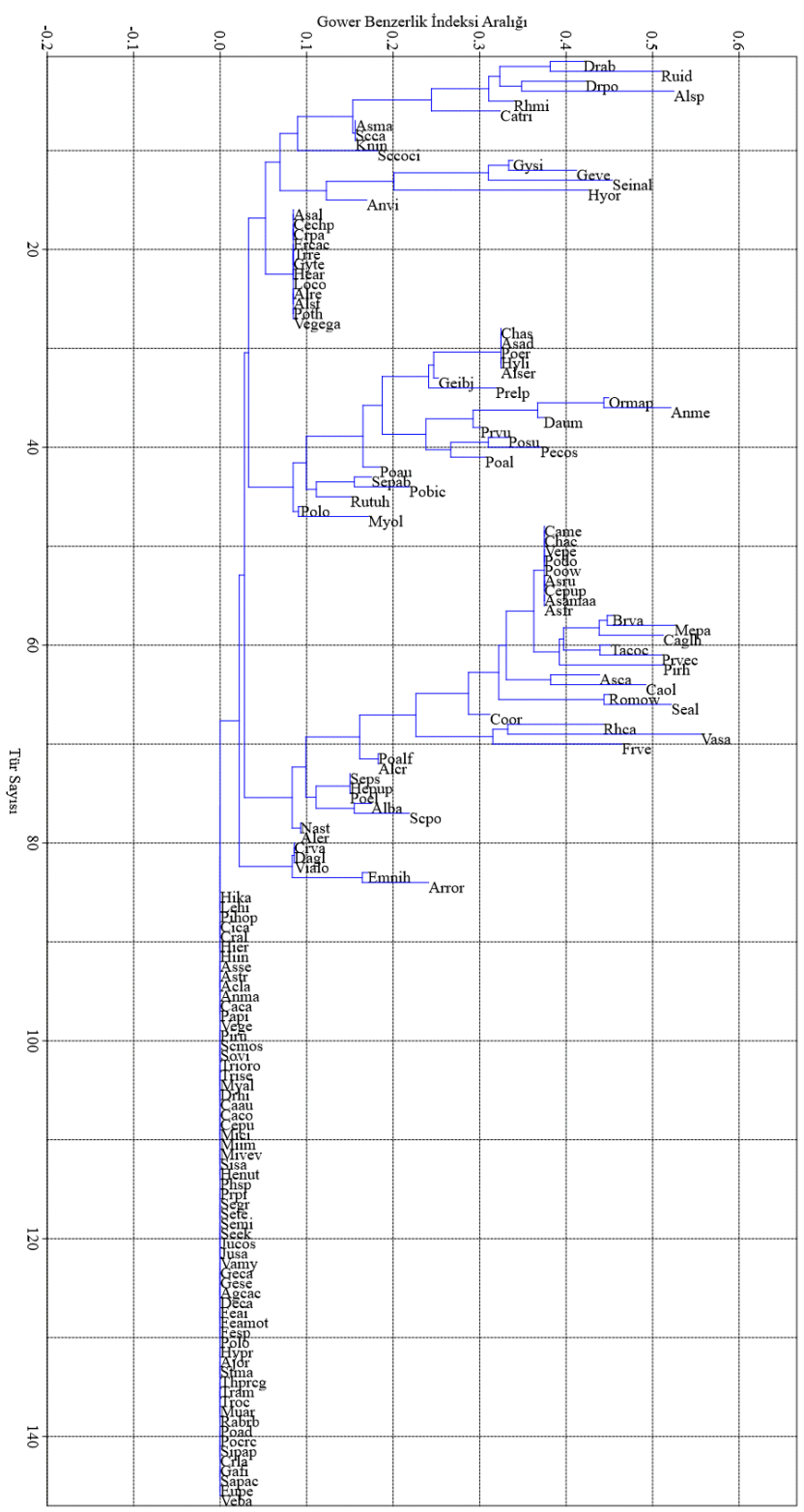

Şekil 5. Örnek alanlarda bulunan taksonların tür kompozisyonları dendogramı (\%40 ve üzeri bulunma oranına göre). 
Taksonların Bazı Morfolojik ve Estetik Özelliklerine Göre Değerlendirilmesi

Çalışma alanındaki alpin kayalık habitatların sahip olduğu bitki kompozisyonları değerlendirilirken kompozisyonu oluşturan taksonların morfolojik ve estetik özellikleri de önem kazanmaktadır. Bu nedenle örnek kayalık alanlarda tespit edilen taksonların genel olarak hangi özelliklerinin öne çıktığını belirlemek için, renk özelliği (çiçek, meyve, yaprak), dokusu, formu, yaşam formu ve çiçeklenme dönemi gibi özelliklerini içeren bir değerlendirme tablosu oluşturulmuştur (Ek Çizelge). Örnek kayalık alanlarda tespit edilen bitki taksonlarının bulunma değerine göre $\% 40$ ve üzeri olanlara ait bazı morfolojik ve estetik özeliklerin genel tablosu ise Çizelge 2 'de verilmiştir. Buna göre, örnek alanlarda bulunan taksonların morfolojik ve estetik özellikleri, bulunma yüzdelerine göre aşağıdaki gibi özetlenebilir:

Çiçek rengi bakımından iki kontrast renk grubu öne çıkmaktadır; sarı çiçekli bitkiler (\%26.7) ve mavi-mor-eflatun-pembe çiçekli bitkiler (\%32.1), bu iki renk grubuna katılan diğer dengeleyici renk grubu ise beyaz-krem renkli çiçeklerdir (\%23). Meyve özellikli bitkiler kayalık habitatlarda çok fazla öne çıkmamakla birlikte (\% 3.7) yaprak rengi bakımından yeşil renk hakim durumdadır (\%93.6). Doku karakteri bakımından orta dokulu bitkiler (\%57.2), ince dokulu (\%34.2) ve kaba dokulu (\%8.6) bitkilerden daha fazladır. Çiçek ve gövde kurulu dik form özelliğine sahip taksonlar (\% 32.6), çiçek kurulu dik gövde kurulu rozet/ küme/ sürünücü-yayılıcl/ kompakt forma sahip taksonlardan (\%40.1) nispeten fazla olmakla birlikte, çiçek ve gövde kurulu eğik/ eğik yayılıcı/ sürünücü/ küme/ rozet küme/ kompakt forma sahip taksonlar da (\%20.9) kayalık habitatlarda kompozisyona katılmaktadır.

Örnek kayalık alanlarda tasarım özellikleri bakımından kontrast renk ve form özeliğine sahip taksonların biraraya gelmesi, görsel çekiciliği arttıran bir faktör olarak değerlendirilebilir. Algılanabilirliği fazla olan sürünücü, yayılıcı ve yastık karakterdeki herdem yeşil odunsu taksonların (Rhododendron caucasium, Juniperus sabina, Juniperus communis, Empetrum nigrum gibi) kayalık komposizyonda öne çıkmasına rağmen çeşitlilik bakımından otsu bitkiler daha fazla sayıdadır. Kayalık habitatlardaki bitki kompozisyonlarında, herdemyeşil odunsu taksonlar yamalar halinde dikkati çekerken (Rhododendron ve Juniperus cinsleri gibi), otsu taksonlar eğer kaya yüzeylerinde ise spotlar halinde, eğer kaya yakın çevresindeler ise renkli geniş yüzeyler olarak dikkati çekmektedirler. Aynı şekilde Vaccinium myrtillus gibi yayılıcı karakterde olan yaprak döken odunsu taksonlar da kayalık habitatlarda kitleler halinde bulunabildiklerinden, özellikle otsu bitkilerin etkisinin azaldığı sonbahara doğru, yapraklarının kızarmasıyla doğal kompozisyondaki görsel etkiyi arttırarak sürekli kılmaktadırlar.

Doğal bitki türleri ve peyzaj çalışmalarında kullanılabilirlikleri ile ilgili daha önce yapılan bazı çalışmalara göre birçok bitkiden işlevsel ve estetik açıdan faydalanmanın mümkün olduğu görülmektedir (Güçlü 1988; Acar 1997; Acar 2003; Acar ve ark. 2004). Dolayısıyla alpin kayalık alanlarda tespit edilen bazı taksonlar da bu bağlamda değerlendirilebilir. Alpin bitkilerin zorlu 
çevresel koşullara adapte olabilmeleri sayesinde kendi bölgelerinde yaşamlarını sürdürebiliyor olmaları, fiziksel olarak çevresel koşulların daha iyi olduğu alanlarda yaşayamayacakları anlamına gelmemektedir. Aksi halde bu bitkileri günümüzde kültür bitkileri (süs bitkisi) olarak yakın çevremizde kullanamazdık (Good and Millward 2007). Birçok ekolojist, bakım için daha az müdahale gerektiren daha doğal bir vejetasyon modelinin peyzaj uygulamalarında maliyeti düşürebileceğini belirtmektedir (Bradshaw ve Handley 1982). Bir alanın tasarımında o alanda halihazırda bulunan doğal türlerin kullanılması genellikle estetik ve sürdürülebilirlik açısından daha uygun görülmektedir. Doğal türler de genellikle bölgenin arazi koşullarına önceden adapte oldukları ve birçok hayvan türünü üzerinde barındırdığı düşüncesiyle sürdürülebilir peyzaj açısından daha uygun bulunmaktadır (Özgüner 2003). Dolayısıyla doğal bitkilerin kullanılması kapsamında alpin kaya bitkilerinin değerlendirilmesi de bu bağlamda önemlidir. Alpin bitkilerin yetişebileceği en uygun ortam olarak doğal kaya bahçeleri oluşturmak, doğadaki gibi eğimli ve drenajı iyi olacak şekilde kaya bahçeleri tasarlamak bu bitkiler için en ideal sonucu verecektir (GreyWilson 2000). Doğalcı yaklaşımlarla bu bahçeler oluşturulurken kaya ve bitki ilişkisini doğru bir şekilde kurabilmek için, fon oluşturma, mekanı tanımlama, çeşitlilik yaratma ve yerine geçme - ikame (olmayan bir objenin yerini kaya ile tamamlama, örneğin kışın bitkiler etkilerini kaybettiğinde o boşluğu kaya ile tamamlama) gibi başlıca 4 temel ilke başarılı bir sonuç elde etmede göz önüne alınmalıdır (Dubé ve Campbell 1999).

Çizelge 2. Örnek alanlarda tespit edilen bitki türlerinin bazı morfolojik ve estetik özellikleri (toplam 187 taksonun özelliklerine göre verilmiştir).

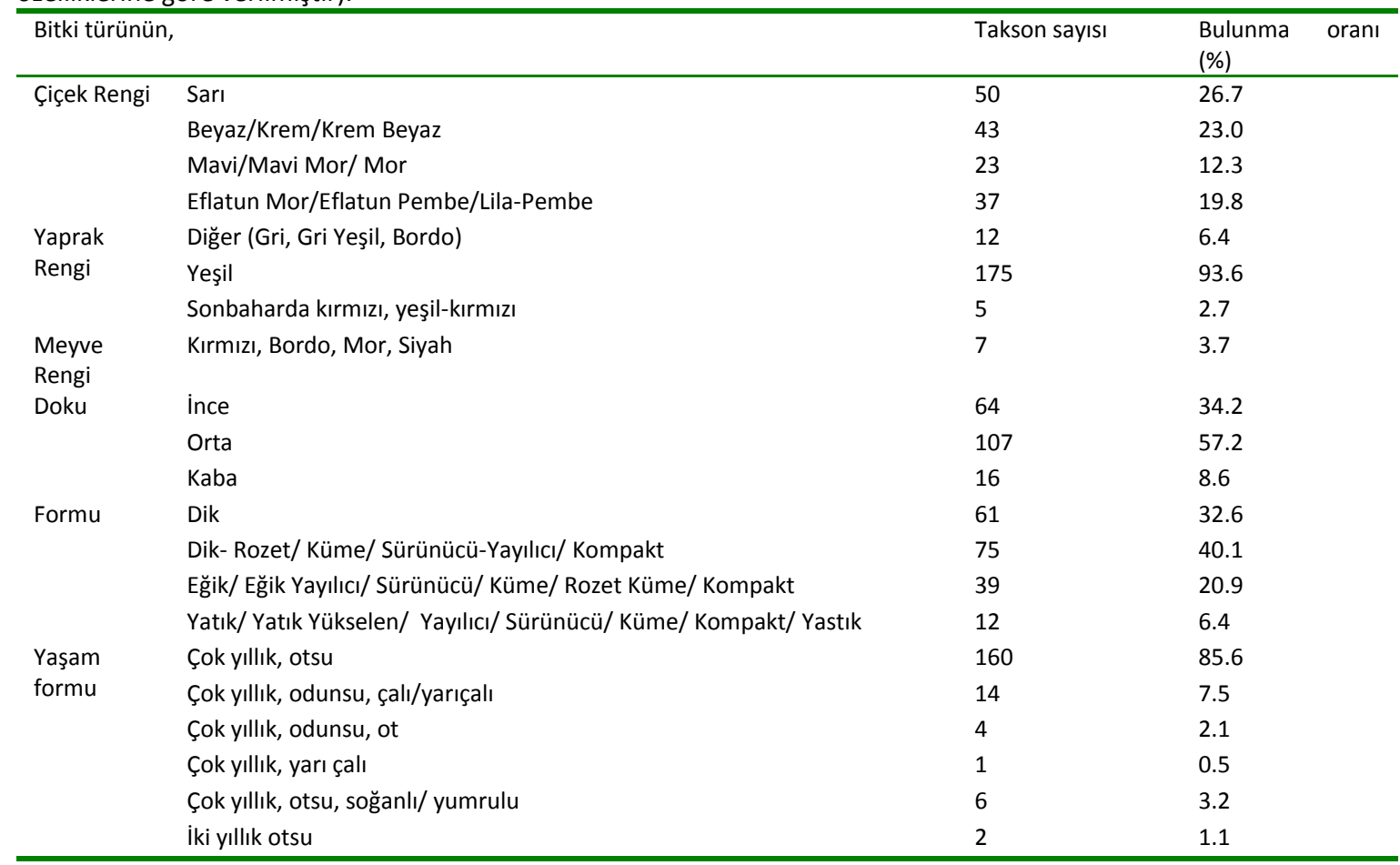




\section{SONUÇ VE ÖNERILER}

$\mathrm{Bu}$ çalışma sonucunda, alpin kayalık habitatların oldukça sınırlı ve küçük ölçekli alanlar olmasına rağmen floristik çeşitlilik bakımından zengin olduğu belirlenmiştir. Özellikle estetik değeri yüksek ve fonksiyonel bakımdan kullanışlı olabilecek birçok çok yıllık bitki taksonu tespit edilmiştir. Bu bağlamda, HVMP örneğinde alpin kayalık habitatlarda tespit edilen bitki kompozisyonları değerlendirildiğinde, bitkisel tasarımlarda kullanılabilecek bitki türleri ve kompozisyonlardaki fonksiyonlarına yönelik;

- Kompozisyonda yapısal olarak, yıl boyu etkili olan daha çok herdem yeşil türlerin kullanılabileceği,

- Kompozisyonda vurgu oluşturmak için daha çok çiçek güzelliği ile dikkat çeken tek veya gruplar halinde kullanıldığında etkili olabilecek olan türlerin kullanılabileceği,

- Kompozisyonda dolgu ve destek oluşturmak için, daha çok yayılıcı, yastık, küme gibi formların yanı sıra dik forma sahip türlerin kullanılabileceği önerilebilir.

Burada belirtilen başlıklara göre, HVMP'da belirlenen ve süs bitkisi olarak değerlendirilebilecek bazı taksonlar ve bu taksonların bitkisel kompozisyonlardaki fonksiyonları Çizelge 3'de sunulmıştur.

Kayalık habitatlar, bu ortamlara adapte olabilen ve bu ortamlarda hayatta kalmayı başaran pek çok bitki ve hayvan topluluğu için genellikle insan baskısının çok fazla hissedilmediği önemli yaşam alanlarıdır. Ancak doğal kayalık habitatların dışında günümüzde insan faaliyetleri sonucunda da (madenler, yollar, baraj ve HES'ler vb.) kayalık alanlar ortaya çıkmaktadır. Bu alanlar daha sonra yine insan eliyle iyileştirilmeye ve onarılmaya çalışılmaktadır. Dolayısıyla ekolojik ve fonksiyonel gerekçelerle bu alanların ve bu alanlara adapte olabilen bitki türlerinin değerlendirilmesi gerekmektedir.

Birçok bitki türü, insanlara sayısız yararı olabilecekken biz farkında olmadan yok olmakta veya ihmal edilmektedir. Bu nedenle öncelikle yapılması gereken, bu bitkileri muhafaza etmek ve daha sonra ise hala sahip olduğumuz bitkilerin üretilerek koruma altına alınmasını sağlamaktır.

HVMP içerisinde tespit edilen birçok takson, alpin bahçeler veya kaya bahçeleri gibi çeşitli kullanım alanlarında değerlendirilebilir. Uygun ortamları sağlayarak bu bitkilerin sergilenmesi, insanların ilgisini çekecek ve bulundukları alanı cazip kılacaktır. Aynı zamanda bilimsel ve rekreasyonel amaçlara hizmet edebilmesi bakımından hem ulusal hem de uluslararası ölçekte yararlı olacaktır.

\section{Teşekkür}

Bu çalışmada, KTÜ-BAP (2009.113.003.1) tarafından desteklenen "Kayalık Habitatların Peyzaj Değerlendirmesi Üzerine Bir Araştırma: Hatila Vadisi Milli Parkı (Artvin) Örneği" adlı doktora tezi çalışması verilerinden yararlanılmıştır. 
Çizelge 3. HVMP'da belirlenen ve süs bitkisi olarak değerlendirilebilecek bazı taksonlar ve bu taksonların bitkisel kompozisyonlardaki fonksiyonları.

\begin{tabular}{|c|c|}
\hline $\begin{array}{l}\text { Kompozisyondaki } \\
\text { Fonksiyonu }\end{array}$ & Bitki Türleri \\
\hline $\begin{array}{c}\text { Yapısal } \\
\text { (Kalıcı ve yaprak } \\
\text { dökmeyen) }\end{array}$ & $\begin{array}{l}\text { Daphne glomerata, Empetrum nigrum ssp. hermaphroditum, Juniperus communis var. } \\
\text { saxatalis, J. sabina, , Rhododendron x davisianum, } R \text {. caucasium }\end{array}$ \\
\hline Odak, Vurgu & $\begin{array}{l}\text { Anthemis marschalliana, A. melanoloma, Aster alpinus, A. caucasicus, Centaurea } \\
\text { cheiranthifolia, C. pulcherrima, Erigeron caucasicus, Tanacetum coccineum, } \\
\text { Tripleurospermum oreades, T. sevanense, Myosotis alpestris, M. amoena, M. } \\
\text { lithospermifolia, M. olympica, Draba hispida, D. polytricha, Campanula aucheri, C. } \\
\text { collina, C. glomerata, C. olympica, C. tridentata, Arenaria rotundifolia, Dianthus } \\
\text { floribundus, Gypsophila simulatrix, G. tenuifolia, Minuartia circassica, M. imbricata, M. } \\
\text { verna, Phedimus spurius, Prometheum pilosum, Sedum alpestre, S. gracile, S. pallidum, } \\
\text { S. tenellum, Sempervivum minus, S. ekimii, Scabiosa columbaria, S. caucasica, } \\
\text { Gentianella caucasea, Gentiana septemfida, G.verna, Geranium cinereum, G. ibericum, } \\
\text { G. psilostemon, Hypericum bithynicum, H. linarioides, H. orientale, H. pruinatum, Crocus } \\
\text { vallicola, Ajuga orientalis, Prunella vulgaris, Stachys byzantina, S. iberica, S. macrantha, } \\
\text { Scutellaria pontica, Allium djimilense, A.schoenoprasum, Muscari armeniacum, } \\
\text { M.coeleste, Scilla winogradowii, Dactylorhiza umbrosa, Orchis mascula, Polygala } \\
\text { alpestris, P. supina, Androsace villosa, Primula auriculata, P. elatior, P. veris, Anemone } \\
\text { narcissiflora, Saxifraga exarata, S. paniculata, Pedicularis comosa, Potentilla } \\
\text { oweriniana, Trifolium polyphyllum, Veronica baranetzkii, V. gentianoides, V. } \\
\text { peduncularis, Valeriana alliariifolia, V. saxicola, Viola altaica }\end{array}$ \\
\hline Dolgu, Destek & $\begin{array}{l}\text { Astrantia maxima, Pimpinella rhodantha, Antennaria dioica, Gnaphalium stewartii, } \\
\text { Scorzonera mollis, Senecio integrifolius, S. pseudo-orientalis, Solidago virgaurea, } \\
\text { Asyneuma amplexicaule, Cerastium purpurascens, Silene saxatilis, Helianthemum } \\
\text { nummularium, Carex pontica, Vaccinium myrtillus, Luzula slyvatica, Thymus praecox, } \\
\text { Astragalus frickii, Coronilla orientalis, Lotus corniculatus, Medicago papillosa, Trifolium } \\
\text { ambiguum, T. ochroleucum, Epilobium angustifolium, Polygonum bistorta, Thalictrum } \\
\text { minus, Alchemilla barbatiflora, A. crinita, A. erythropoda, A. retinervis, A. sericata, A. } \\
\text { sericea, A. stricta, Cotoneaster nummularia, Potentilla adscharica, P. doddsii, P. crantzii, } \\
\text { P. elatior, P. erecta, Sibbaldia parviflora, Cruciatalaevipes, Galium fissurense, Euphrasia } \\
\text { pectinata, Viola sieheana, Asplenium adiantum-nigrum, A. ruta - muraria, A. } \\
\text { trichomanes, Nardus stricta, Deschampsia caespitosa, Tragopogon reticulatus, Festuca } \\
\text { airoides, Festuca amethystina }\end{array}$ \\
\hline
\end{tabular}

\section{KAYNAKLAR}

Acar C (1997) Trabzon ve çevresinde yetişen doğal bazı yer örtücü bitkilerin peyzaj mimarlığında değerlendirilmeleri üzerine bir araştırma, Doktora Tezi, Karadeniz Teknik Üniversitesi, Fen Bilimleri Enstitüsü, Trabzon

Acar C (2003) A study on the ground layer species composition in rocky, roadside and forest habitats in trabzon province. Turkish Journal of Botany 27(4): $255-275$

Akman Y, Ketenoğlu O, Kurt F (2011) Vejetasyon ekolojisi ve araştırma metotları. Palme Yayıncılık, Ankara, s.292

Acar C, Acar H, Altun L (2004) The diversity of ground cover species in rocky, roadside and forest habitats in trabzon (North-Eastern Turkey). Biologia Bratislava 59(4): 477-499
Acar C, Acar H, Eroğlu E (2007) Evaluation of ornamental plant resources to urban biodiversity and cultural changing: a case study of residential landscapes in Trabzon city (Turkey). Building and Environment 42: 218-229

Acar C, Sarı D (2010) Kentsel yerleşim alanlarındaki bitkilerin peyzajda kullanım tercihleri açısından değerlendirilmesi: Trabzon kenti örneği. Ekoloji 19(74): 173-180

Anonim (2005) Artvin II Gelişme Planı, Çevre ve mekânsal gelişme sektörü raporu, Artvin

Anonim (2014) Doğa Koruma ve Milli Parklar Genel Müdürlüğü, Hatila Vadisi Milli Parkı, http://www.milliparklar.gov.tr/mp/hatilavadisi/ind ex.htm, 10.09.2014

Anşin R, Özkan Z C, Eminağaoğlu Ö (2000) Artvin -Atila (Hatilla) Vadisi Milli Parkının vejetasyon yapısına 
genel bir bakış. Kafkas Üniversitesi Artvin Orman Fakültesi Dergisi 1 (1): 59-71

Atay S, Güleryüz G, Orhun C, Seçmen Ö, Vural C (2009) Dağlarımızdaki zenginlik Türkiye'nin 120 alpin bitkisi. Dönence Basım ve Yayın Hizmetleri, İstanbul

Booth N (1990) Basic elements of landscape architectural design. Waveland Pres, Inc Illinois, USA

Bradshaw A D, Handley J (1982) An ecological approach to landscape design: principles and problems. Landscape Design 138: 30-34

Coates F, Kirkpatrick J B (1992) Environmental relationships and ecological responses of some higher plant species on rock cliffs in northern Tasmania. Australian Journal of Ecology 17: 441449

Davis P H (1965 - 1988) Flora of Turkey and East Aegean Islands. Vol. I-XI, Edinburg

Dubé RL, Campbell F C (1999) Natural stonescapes, the art and craft of stone placement. Transcontinental Printing, Canada

Evans A (1981) Alpines '81: Report of the 5th international rock garden plant conference and show, Conference report. Nottingham, UK

Good J E G, Millward D (2007) Alpine plants ecology for gardeners. Timber Press, Portland, Oregon, USA

Good R B (1992) L'aménagment de la végétation dans les Alpes Australiennes. Revenue de Géographie Alpine 80 (2): 361-379

Grey-Wilson C (2000) Alpines, the new plant library. Lorenz Books, NewYork, USA

Güçlü K (1988) Erzurum'da doğal olarak yetişen bazı bitkilerin taş ve kaya bahçeleri ile kuru duvarlarda kullanımları üzerinde bir araştırma. Atatürk Üniversitesi Ziraat Fakültesi Dergisi 19(1): 35-49

Karaer F, Terzioğlu S (2012) Hatila Vadisi Milli Parkı uzun devreli gelişme planı, analitik etüt raporu. Ortadoğu
Ormancılık Proje Etüt ve Müşavirlik Ticaret A.Ş. (ODOPEM), Ankara

Karaşah B (2006) Kentsel dokuda bitkilendirme tasarımında yapılan yanlışlıkların belirlenmesi; Trabzon Örneği, Yüksek Lisans Tezi, KTÜ Fen Bilimleri Enstitüsü, Trabzon

Kowarik I (1995) On the role of alien species in urban flora and vegetation. Urban Ecology 4: 321-338

Körner C (1995) Alpine plant diversity: A global survey and functional interpretations. In: Chapin FS and Körner C (Eds) Arctic and alpine biodiversity: patterns, causes and ecosystem consequences, Springer, Heildelberg, Germany, pp 45-62

Main B Y (1997) Granite outcrops: A collective ecosystem. Journal of the Royal Society of Western Australia 80:113-122

Özgüner H (2003) Kentsel peyzajda doğal stilin fonksiyonel değerleri ve bunların klasik stille karşılaştırılması. Süleyman Demirel Üniversitesi Orman Fakültesi Dergisi A (2): 19-36

Terzioğlu S (1998) Uzungöl (Trabzon-Çaykara) ve çevresinin flora ve vejetasyonu. Doktora Tezi, KTÜ Fen Bilimleri Enstitüsü, Trabzon

Terzioğlu S, Anşin R, Kılınç M, Acar C (2007) Vascular plant diversity in Solaklı watershed in Northeastern Turkey. Phytologia Balcanica 13 (2): 213-222

Thompson K, Austin K C, Smith R M, Warren P H, Angold P G, Gaston K J (2003) Urban domestic gardens (I): putting small-scale plant diversity in context. Journal of Vegetation Science 14: 71-78

Turner K, Lefler L, Freedman B (2005) Plant communities of selected urbanized areas of Halifax, Nova Scota, Canada. Landscape and Urban Planning 71: 191-206

TÜBіTAK (2002) Biyolojik çeşitliliğin korunması ve sürdürülebilir kalkınma, VIZYON 2023, TÜBITAK 
Ek Çizelge Örnek alanlarda tespit edilen bitki taksonları ve bazı morfolojik özellikleri (\%40 ve üzeri bulunma oranına sahip türler )

\begin{tabular}{|c|c|c|c|c|c|c|c|c|c|c|}
\hline $\begin{array}{c}\text { Takson } \\
\text { no }\end{array}$ & $\begin{array}{l}\text { Bulunma } \\
\text { oranı (\%) }\end{array}$ & Takson adı & $\begin{array}{l}\text { Kısaltma } \\
\text { lar }\end{array}$ & Yaşam formu & $\begin{array}{l}\text { Çiçeklenme } \\
\text { dönemi }\end{array}$ & Çiçek rengi & Yaprak rengi & $\begin{array}{l}\text { Meyve } \\
\text { rengi }\end{array}$ & Doku & Form \\
\hline 1 & 100 & $\begin{array}{l}\text { Anthemis marschalliana Willd. subsp. pectinata } \\
\text { (Boiss.) Grierson }\end{array}$ & Anma & Çok Yıllık, Otsu & $7-8$ & Sarı & Yeşil, Gri Yeşil & & Orta & Dik \\
\hline 2 & 100 & Tripleurospermum sevanense (Manden.) Poeb. & Trse & Çok Yıllık, Otsu & $6-7$ & Beyaz & Yeşil & & Orta & Dik, Küme \\
\hline 3 & 100 & $\begin{array}{l}\text { Scorzonera mollis Bieb. subsp. szowitzii (DC.) } \\
\text { Chamberlain }\end{array}$ & Scmo & Çok Yıllık, Otsu & $4-6$ & Sarı & Yeşil & & İnce & Dik \\
\hline 4 & 100 & Crepis alpestris (Jacq.) Tausch & Cral & Çok Yıllık, Otsu & $6-8$ & Sarı & Yeşil, Gri Yeşil & & İnce & Dik, Rozet \\
\hline 5 & 100 & Leontodon hispidus L. var. hispidus L. & Lehi & Çok Yıllık, Otsu & $7-9$ & Sarı & Yeşl & & İnce & Dik, Rozet \\
\hline 6 & 100 & $\begin{array}{l}\text { Pilosella hoppeana (Schultes) C. H. \& F. W. Schultz } \\
\text { subsp. pilisquama (NP.) Sell \& West }\end{array}$ & Piho & Çok Yıllık, Otsu & $5-9$ & Sarı & Yeşil & & İnce & Dik, Rozet \\
\hline 7 & 100 & Cirsium caucasicum (Adams) Petrak & Cica & Çok Yıllık, Otsu & $8-8$ & Açık Pembe & Yeşil & & Orta & Dik \\
\hline 8 & 100 & Draba hispida Willd. & Drhi & Çok Yıllık, Otsu & $4-8$ & Sarı & Yeşil & & İnce & Dik, Rozet \\
\hline 9 & 100 & Campanula aucheri A. DC. & Caau & Çok Yıllık, Otsu & $6-8$ & Mor, Mavi & Yeşil & & Orta & $\begin{array}{l}\text { Dik, } \\
\text { Rozet,Küme }\end{array}$ \\
\hline 10 & 100 & Cerastium purpurascens Adams & Cepu & Çok Yıllık, Otsu & $6-8$ & Beyaz & Yeşil & & İnce & Eğik, Yayılııı \\
\hline 11 & 100 & Phedimus spurius (M. Bieb.) 't Hart & Phsp & Çok Yıllık, Otsu & $7-8$ & Pembe & Yeşil & & Orta & $\begin{array}{c}\text { Dik, } \\
\text { Sürünücü- } \\
\text { yayılıcı }\end{array}$ \\
\hline 12 & 100 & Gentiana septemfida Pallas & Gese & Çok Yıllık, Otsu & $7-8$ & Mavi & Yeşil & & Orta & Dik \\
\hline 13 & 100 & Agrostis capillaris L. var. capillaris L. & Agca & Çok Yıllık, Otsu & $6-8$ & & Yeşil & & İnce & Dik \\
\hline 14 & 100 & $\begin{array}{l}\text { Festuca amethystina L. subsp. orientalis Krajina var. } \\
\text { turcica Markgr - Damenb. (Endemik) }\end{array}$ & Feam & Çok Yıllık, Otsu & $7-7$ & & Yeşil & & İnce & Dik, Kompakt \\
\hline 15 & 100 & Festuca airoides Lam. & Feai & Çok Yıllık, Otsu & $7-8$ & & Yeşil & & İnce & Dik, Kompakt \\
\hline 16 & 100 & $\begin{array}{l}\text { Thymus praecox Opiz subsp. caucasicus (Ronniger) } \\
\text { Jalas var. grossheimi (Ronniger) Jalas }\end{array}$ & Thprca & $\begin{array}{l}\text { Çok Yıllık, Odunsu } \\
\text { Ot }\end{array}$ & $5-8$ & $\begin{array}{l}\text { EflatunPembe } \\
\text {-Mor }\end{array}$ & Yeşil & & Orta & Eğik, Yayılııı \\
\hline 17 & 100 & Ajuga orientalis L. & Ajor & Çok Yıllık, Otsu & $4-7$ & Mor & Yeşil & & Orta & Dik, Rozet \\
\hline 18 & 100 & Stachys macrantha (C. Koch) Stearn & Stma & Çok Yıllık, Otsu & $6-9$ & $\begin{array}{l}\text { Eflatun, } \\
\text { Pembe }\end{array}$ & Yeşil & & Orta & Dik, Rozet \\
\hline 19 & 100 & Trifolium ochroleucum Huds. & Troc & Çok Yıllık, Otsu & $6-7$ & Krem Beyaz & Yeşil & & Orta & Dik, Küme \\
\hline 20 & 100 & Trifolium ambiguum Bieb. & Tram & Çok Yıllık, Otsu & $6-8$ & $\begin{array}{l}\text { Pembemsi } \\
\text { Krem Beyaz }\end{array}$ & Yeşil & & Orta & $\begin{array}{c}\text { Yatık } \\
\text { Yükselen, } \\
\text { Yayılıcı }\end{array}$ \\
\hline 21 & 100 & $\begin{array}{l}\text { Ranunculus brachylobus Boiss. \& Hoh. subsp. } \\
\text { brachylobus (L.) Swartz }\end{array}$ & Rabrb & Çok Yıllık, Otsu & $6-8$ & Sarı & Yeşil & & İnce & Dik, Küme \\
\hline 22 & 100 & Potentilla adscharica Somm. \& Lev. ex Keller & Poad & Çok Yıllık, Otsu & $4-7$ & Sarı & Yeşil & & Orta & $\begin{array}{l}\text { Eğik, Yayılıcı, } \\
\text { Küme }\end{array}$ \\
\hline 23 & 100 & $\begin{array}{l}\text { Potentilla crantzii (Crantz) G. Beck ex Fritsch var. } \\
\text { crantzii (Crantz) G. Beck ex Fritsch }\end{array}$ & Pocrc & Çok Yıllık, Otsu & $6-9$ & Sarı & Yeşil & & İnce & $\begin{array}{l}\text { Eğik, Yayılıcı, } \\
\text { Küme }\end{array}$ \\
\hline
\end{tabular}


Alpin kayalık habitatlardaki doğal bitki taksonlarının bitkisel tasarımlardaki fonksiyonları bakımından değerlendirilmesi

\begin{tabular}{|c|c|c|c|c|c|c|c|c|c|c|}
\hline $\begin{array}{c}\text { Takson } \\
\text { no }\end{array}$ & $\begin{array}{l}\text { Bulunma } \\
\text { oranı (\%) }\end{array}$ & Takson adı & $\begin{array}{l}\text { Kısaltma } \\
\text { lar }\end{array}$ & Yaşam formu & $\begin{array}{l}\text { Çiçeklenme } \\
\text { dönemi }\end{array}$ & Çiçek rengi & Yaprak rengi & $\begin{array}{l}\text { Meyve } \\
\text { rengi }\end{array}$ & Doku & Form \\
\hline 24 & 100 & Sibbaldia parviflora Willd. var.parviflora & Sipa & $\begin{array}{l}\text { Çok Yillık, Odunsu } \\
\text { Ot }\end{array}$ & $6-7$ & Sarı & Yeşil & & Orta & $\begin{array}{l}\text { Eğik, Yayılııı, } \\
\text { Küme }\end{array}$ \\
\hline 25 & 100 & Cruciata laevipes Opiz. & Crla & Çok Yıllık, Otsu & $4-7$ & Sarı & Yeşil & & İnce & Dik \\
\hline 26 & 100 & $\begin{array}{l}\text { Saxifraga paniculata Miller subsp. cartilaginea } \\
\text { (Willd.) D. A. Webb }\end{array}$ & Sapac & Çok Yıllık, Otsu & $4-8$ & Beyaz & Yeşil & & İnce & Dik, Rozet \\
\hline 27 & 100 & Veronica gentianoides Vahl. & Vege & Çok Yıllık, Otsu & $5-8$ & Mavi, Mor & Yeşil & & Orta & Dik \\
\hline 28 & 100 & Euphrasia pectinata Ten. & Eupe & Tek Yıllık, Otsu & $5-8$ & Beyaz, Krem & Yeşil & & Orta & Dik \\
\hline 29 & 100 & Campanula collina Sims. & Caco & Çok Yıllık, Otsu & $6-8$ & Mor & Yeşil & & Orta & Dik, Rozet \\
\hline 30 & 100 & $\begin{array}{l}\text { Helianthemum nummularium (L.) Miller subsp. } \\
\text { tomentosum (Scop.) Schinz \& Thellung }\end{array}$ & Henu & Çok Yıllık, Yarı Çalı & $4-8$ & Sarı & Yeşil & & Orta & Eğik, Yayılıcı \\
\hline 31 & 100 & Hypericum pruinatum Boiss \& Bal. & Hypr & Çok Yıllık, Otsu & $7-8$ & Sarı & Yeşil & & Orta & Dik, Küme \\
\hline 32 & 100 & Carum caucasicum (Bieb.) Boiss. & Caca & Çok Yıllık, Otsu & $8-8$ & Beyaz & Yeşil & & Orta & Dik \\
\hline 33 & 100 & Minuartia circassica (Albow) Woron. & Mici & Çok Yıllık, Otsu & $7-8$ & Beyaz & Yeşil & & Orta & $\begin{array}{l}\text { Dik, Kompakt, } \\
\text { Küme }\end{array}$ \\
\hline 34 & 100 & Sedum tenellum Bieb. & Sete & Çok Yıllık, Otsu & $6-8$ & Pembe & Yeşil & & İnce & Eğik, Yayılıcı \\
\hline 35 & 100 & Poa longifolia Trin. & Poal & Çok Yıllık, Otsu & 7-7 & & Yeşil & & İnce & Dik \\
\hline 36 & 100 & Galium fissurense Ehrend \& Schönb. & Gafi & Çok Yıllık, Otsu & $5-8$ & Beyaz & Yeşil & & Orta & Dik \\
\hline 37 & 100 & Achillea latiloba Ledeb. Ex Nordm. & Acla & Çok Yıllık, Otsu & $6-8$ & Beyaz & Yeşil & & Orta & Dik \\
\hline 38 & 100 & Silene saxatilisSims & Sisa & Çok Yıllık, Otsu & $6-8$ & Krem Beyaz & Yeşil & & İnce & Dik, Rozet \\
\hline 39 & 100 & Pastinaca pimpinellifolia Bieb. & Papi & Çok Yıllık, Otsu & $7-7$ & Krem & Yeşil & & Orta & Dik \\
\hline 40 & 100 & Hieracium erythrocarpum Peter (Endemik) & Hier & Çok Yıllık, Otsu & $7-8$ & Sarı & Yeşil & & Orta & Dik \\
\hline 41 & 100 & $\begin{array}{l}\text { Hieracium karagoellense (Zahn) Sell \& West } \\
\text { (Endemik) }\end{array}$ & Hika & Çok Yıllık, Otsu & $7-7$ & Sarı & Yeşil & & Orta & Dik \\
\hline 42 & 100 & Gentianella caucasea (Loddiges ex Sims) Holub & Geca & İki Yıllık, Otsu & $7-8$ & Eflatun & $\begin{array}{l}\text { Bordomsu } \\
\text { Yeşil }\end{array}$ & & Orta & Dik \\
\hline 43 & 100 & Asplenium septentrionale (L.) Hoffm. & Asse & Çok Yıllık, Otsu & & & Yeşil & & İnce & $\begin{array}{l}\text { Eğik, } \\
\text { Sürünücü }\end{array}$ \\
\hline 44 & 100 & Asplenium trichomanes $\mathrm{L}$. & Astr & Çok Yıllık, Otsu & & & Yeşil & & Orta & $\begin{array}{l}\text { Yatık } \\
\text { Yükselen, } \\
\text { Küme }\end{array}$ \\
\hline 45 & 100 & Pilosella x ruprechtii (Boiss.) Sell \& West & Piru & Çok Yıllık, Otsu & $6-6$ & Sarı & Yeşil & & İnce & Dik \\
\hline 46 & 100 & $\begin{array}{l}\text { Solidago virgaurea L. subsp. alpestris (Waldst. \& Kit.) } \\
\text { Gaudin }\end{array}$ & Sovi & Çok Yıllık, Otsu & $8-9$ & Sarı & Yeşil & & Orta & Dik \\
\hline 47 & 100 & Vaccinium myrtillus L. & Vamy & $\begin{array}{l}\text { Çok Yıllık, Odunsu } \\
\text { Çalı }\end{array}$ & $5-7$ & Krem & $\begin{array}{c}\text { Yeşil, } \\
\text { Sonbaharda } \\
\text { Kırmızı }\end{array}$ & Mor & Kaba & $\begin{array}{l}\text { Kompakt, } \\
\text { Yastık }\end{array}$ \\
\hline 48 & 100 & Sempervivum minus Turrill (Endemik) & Semi & Çok Yıllık, Otsu & $7-9$ & Sarı & $\begin{array}{l}\text { Yeşil, Kırmızı- } \\
\text { Yeşil }\end{array}$ & & Orta & Dik, Rozet \\
\hline 49 & 100 & Sedum gracile C. A. Meyer & Segr & Çok Yıllık, Otsu & $6-8$ & $\begin{array}{l}\text { Krem, Açık } \\
\text { Pembe }\end{array}$ & Yeşil & & İnce & $\begin{array}{l}\text { Eğik, Yayılııı, } \\
\text { Küme }\end{array}$ \\
\hline
\end{tabular}




\begin{tabular}{|c|c|c|c|c|c|c|c|c|c|c|}
\hline $\begin{array}{c}\text { Takson } \\
\text { no }\end{array}$ & $\begin{array}{l}\text { Bulunma } \\
\text { oranı (\%) }\end{array}$ & Takson adı & $\begin{array}{l}\text { Kısaltma } \\
\text { lar }\end{array}$ & Yaşam formu & $\begin{array}{l}\text { Çiçeklenme } \\
\text { dönemi }\end{array}$ & Çiçek rengi & Yaprak rengi & $\begin{array}{l}\text { Meyve } \\
\text { rengi }\end{array}$ & Doku & Form \\
\hline 50 & 100 & Sempervivum ekimii Karaer (Endemik) & Seek & Çok Yıllık, Otsu & $7-9$ & Sarı & $\begin{array}{l}\text { Yeşil, Kırmızı- } \\
\text { Yeşil }\end{array}$ & & Orta & Dik, Rozet \\
\hline 51 & 100 & Festuca L. sp. & Fesp & Çok Yıllık, Otsu & & & Yeşil & & Orta & Dik \\
\hline 52 & 100 & $\begin{array}{l}\text { Tripleurospermum oreades (Boiss.) Rech. Fil. var. } \\
\text { oreades (Boiss.) Rech. Fil.L. }\end{array}$ & Tror & Çok Yıllık, Otsu & $5-8$ & Beyaz & Yeşil & & Orta & Dik, Küme \\
\hline 53 & 100 & $\begin{array}{l}\text { Myosotis alpestris F. W. Schmidt subsp. alpestris F. } \\
\text { W. Schmidt }\end{array}$ & Myal & Çok Yıllık, Otsu & $4-8$ & Mavi & Yeşil & & Orta & Dik \\
\hline 54 & 100 & Minuartia verna (L.) Hiern subsp. verna (L.) Hiern & Mive & Çok Yıllık, Otsu & $7-8$ & Beyaz & Yeşil & & İnce & $\begin{array}{l}\text { Dik, Yayılıcı, } \\
\text { Küme }\end{array}$ \\
\hline 55 & 100 & Prometheum pilosum (Fisch. Ex Bieb.) H. Ohba & Prpi & Çok Yıllık, Otsu & $6-7$ & Pembe & Yeşil & & Orta & Dik, Rozet \\
\hline 56 & 100 & Muscari armeniacum Leichtlin ex Baker & Muar & $\begin{array}{l}\text { Çok Yıllık, Soğanlı, } \\
\text { Otsu }\end{array}$ & $3-5$ & Mor, Mavi & Yeşil & & İnce & Dik \\
\hline 57 & 100 & Deschampsia caespitosa (L.) P. Beauv. & Deca & Çok Yıllık, Otsu & $6-8$ & & Yeşil & & Orta & Dik, Küme \\
\hline 58 & 100 & Hieracium insolitum (Zahn) Juxip & Hiin & Çok Yıllık, Otsu & $7-8$ & Sarı & Yeşil & & İnce & Dik \\
\hline 59 & 100 & Minuartia imbricata (Bieb.) Woronow & Miim & Çok Yıllık, Otsu & $6-8$ & Beyaz & Yeşil & & İnce & $\begin{array}{l}\text { Eğik, } \\
\text { Sürünücü, } \\
\text { Küme }\end{array}$ \\
\hline 60 & 100 & Juniperus sabina L. & Jusa & $\begin{array}{l}\text { Çok Yıllık, } \\
\text { Odunsu, Çalı }\end{array}$ & & & Yeşil & & Kaba & Yayılıcı \\
\hline 61 & 100 & Juniperus communis L. var. saxatalis Pall. & Juco & $\begin{array}{l}\text { Çok Yıllık, } \\
\text { Odunsu, Çalı }\end{array}$ & & & Yeşil & & Kaba & Yayılıcı \\
\hline 62 & 100 & Veronica baranetzkii Bordz. & Veba & Çok Yıllık, Otsu & $5-8$ & Mavi & Yeşil & & İnce & $\begin{array}{l}\text { Eğik, } \\
\text { Sürünücü }\end{array}$ \\
\hline 63 & 92 & Nardus stricta $\mathrm{L}$. & Nast & Çok Yıllık, Otsu & $7-8$ & & Yeşil & & İnce & Dik, Küme \\
\hline 64 & 92 & Viola altaica Ker. Gawl. subsp. oreades(Bieb.) Becker & Vialo & Çok Yıllık, Otsu & $5-7$ & Mor, Sarı & Yeşil & & Orta & Dik \\
\hline 65 & 92 & Alchemilla stricta Rothm. & Alst & Çok Yıllık, Otsu & $6-7$ & Sarı & Yeşil & & Orta & Eğik, Küme \\
\hline 66 & 92 & Helictotrichon argaeum (Boiss.) Parsa (Endemik) & Hear & Çok Yıllık, Otsu & $7-8$ & & Yeşil & & Orta & Dik \\
\hline 67 & 92 & Alchemilla retinervis Buser & Alre & Çok Yıllık, Otsu & $6-7$ & Sarı & Yeşil & & Orta & Eğik, Küme \\
\hline 68 & 92 & Alchemilla erythropoda Juz. & Aler & Çok Yıllık, Otsu & $5-8$ & Sarı & Yeşil & & Orta & Eğik, Küme \\
\hline 69 & 92 & Tragopogon reticulatus Boiss.\& Huet & Trre & Çok Yıllık, Otsu & $4-9$ & Sarı & Yeşil & & Orta & Dik \\
\hline 70 & 92 & Gypsophila tenuifolia Bieb. & Gyte & Çok Yıllık, Otsu & $7-8$ & Beyaz & Yeşil & & Orta & Küme \\
\hline 71 & 92 & Crocus vallicola Herbert & Crva & $\begin{array}{l}\text { Çok Yıllık, Otsu, } \\
\text { Soğanlı }\end{array}$ & $8-10$ & Beyaz, Krem & Yeşil & & İnce & Dik \\
\hline 72 & 92 & Erigeron caucasicus Stev. subsp. caucasicus Stev. & Ercac & Çok Yıllık, Otsu & $6-8$ & $\begin{array}{l}\text { Pembe } \\
\text { Eflatun }\end{array}$ & Yeşil & & İnce & Dik, Rozet \\
\hline 73 & 92 & Polystichum lonchitis (L.) Roth & Polo & Çok Yıllık, Otsu & & & Yeşil & & Orta & Dik \\
\hline 74 & 92 & Aster alpinus $\mathrm{L}$. & Asal & Çok Yıllık, Otsu & $6-8$ & $\begin{array}{l}\text { Pembe } \\
\text { Eflatun }\end{array}$ & Yeşil & & Orta & Dik \\
\hline 75 & 92 & Crepis paludosa (L.) Moench & Crpa & Çok Yıllık, Otsu & $7-8$ & Sarı & Yeşil & & Orta & Dik \\
\hline
\end{tabular}


Alpin kayalık habitatlardaki doğal bitki taksonlarının bitkisel tasarımlardaki fonksiyonları bakımından değerlendirilmesi

\begin{tabular}{|c|c|c|c|c|c|c|c|c|c|c|}
\hline $\begin{array}{c}\text { Takson } \\
\text { no }\end{array}$ & $\begin{array}{l}\text { Bulunma } \\
\text { oranı (\%) }\end{array}$ & Takson adı & $\begin{array}{l}\text { Kisaltma } \\
\text { lar }\end{array}$ & Yaşam formu & $\begin{array}{l}\text { Çiçeklenme } \\
\text { dönemi }\end{array}$ & Çiçek rengi & Yaprak rengi & $\begin{array}{l}\text { Meyve } \\
\text { rengi }\end{array}$ & Doku & Form \\
\hline 76 & 92 & $\begin{array}{l}\text { Centaurea cheiranthifolia Willd. var. purpurascens } \\
\text { (DC.) Wagenitz }\end{array}$ & Cechpur & Çok Yıllık, Otsu & $6-8$ & Eflatun Mor & Yeşil & & Orta & Dik, Rozet \\
\hline 77 & 92 & Potentilla thuringiaca Bernh. ex Link & Poth & Çok Yıllık & $5-7$ & Sarı & Yeşil & & Orta & Dik \\
\hline 78 & 92 & Daphne glomerata Lam. & Dagl & $\begin{array}{l}\text { Çok Yıllık, } \\
\text { Odunsu, Çalı }\end{array}$ & $5-7$ & Krem & Yeşil & & Orta & $\begin{array}{l}\text { Eğik, Yayılııı, } \\
\text { Küme }\end{array}$ \\
\hline 79 & 92 & $\begin{array}{l}\text { Veronica gentianoides Vahl. subsp. gentianoides var. } \\
\text { alpina(Hausskn. ex) Öztürk \& M.A. Fisch. }\end{array}$ & Vegega & Çok Yıllık, Otsu & $5-8$ & Mavi & Yeşil & & İnce & Dik \\
\hline 80 & 92 & Lotus corniculatus L. var. alpinus Ser. & Locoa & Çok Yıllık, Otsu & $7-7$ & Sarı & Yeşil & & Orta & $\begin{array}{l}\text { Eğik, Yayılııı, } \\
\text { Küme }\end{array}$ \\
\hline 81 & 83 & Potentilla aucheriana Th. Wolf & Poau & Çok Yıllık, Otsu & $6-8$ & Sarı & Yeşil & & Orta & Eğik, Yayılıcı \\
\hline 82 & 83 & Alchemilla barbatiflora Juz. & Alba & Çok Yıllık, Otsu & $7-8$ & Sarı & Yeşil & & $\begin{array}{l}\text { Orta, } \\
\text { Kaba }\end{array}$ & Eğik, Küme \\
\hline 83 & 83 & Alchemilla crinita Buser & Alcr & Çok Yıllık, Otsu & $6-6$ & Sarı & Yeşil & & $\begin{array}{l}\text { Orta, } \\
\text { Kaba }\end{array}$ & Eğik, Küme \\
\hline 84 & 83 & Senecio pseudo-orientalis Schischkin & Seps & Çok Yıllık, Otsu & $5-8$ & Sarı & Yeşil & & Orta & Dik \\
\hline 85 & 83 & $\begin{array}{l}\text { Sedum pallidum Bieb. var. bitynicum (Boiss.) } \\
\text { Chamberlain }\end{array}$ & Sepab & Çok Yıllık, Otsu & $6-8$ & Beyaz & $\begin{array}{l}\text { Kırmızımsı } \\
\text { Pembe }\end{array}$ & & İnce & $\begin{array}{l}\text { Dik, } \\
\text { Sürünücü- } \\
\text { Yayılıcı }\end{array}$ \\
\hline 86 & 83 & Knautia involucrata Somm. \& Lev. & Knin & Çok Yıllık, Otsu & $7-8$ & Krem & Yeşil & & Orta & Dik, Rozet \\
\hline 87 & 83 & Astrantia maxima Pallas subsp. maxima Pallas & Asma & Çok Yıllık, Otsu & $6-7$ & $\begin{array}{l}\text { Pembe } \\
\text { Eflatun }\end{array}$ & Yeşil & & Orta & Dik \\
\hline 88 & 83 & $\begin{array}{l}\text { Helictotrichon pubescens(Hudson) Besser ex Schultes } \\
\& \text { Schultes Fil. subsp. pubescens (Hudson) Besser ex } \\
\text { Schultes \& Schultes Fil. }\end{array}$ & Hepu & Çok Yıllık, Otsu & $5-8$ & & Yeşil & & Orta & Dik, Küme \\
\hline 89 & 83 & $\begin{array}{l}\text { Scabiosa columbaria L. subsp. columbaria L. var. } \\
\text { intermedia (Post) Matthews }\end{array}$ & Sccoi & Çok Yıllık, Otsu & $8-9$ & Eflatun Mor & Yeşil & & Orta & Dik \\
\hline 90 & 83 & Scabiosa caucasica Bieb. & Scca & Çok Yıllık, Otsu & $7-8$ & Eflatun Mor & Yeşil & & Orta & Dik \\
\hline 91 & 83 & Poa alpina subsp. fallax F. Herman & Poalf & Çok Yıllık, Otsu & $6-8$ & & Yeşil & & İnce & Dik, Küme \\
\hline 92 & 83 & Potentilla elatior Willd. ex Schlecht. & Poel & Çok Yıllık, Otsu & $6-8$ & Sarı & Yeşil & & Orta & Dik, Yayılıcı \\
\hline 93 & 83 & Myosotis olympica Boiss. & Myol & Çok Yıllık, Otsu & $5-9$ & Mavi & Yeşil & & İnce & Dik \\
\hline 94 & 83 & Rumex tuberosus L. subsp. horozontalis (Koch) Rech. & Rutuh & Çok Yıllık, Otsu & $6-8$ & Bordo & Yeşil & & Kaba & Dik \\
\hline 95 & 83 & Androsace villosa $\mathrm{L}$. & Anvi & Çok Yıllık, Otsu & $5-7$ & Beyaz, Krem & Yeşil & & Orta & $\begin{array}{l}\text { Eğik,Kompakt } \\
\text {, Küme }\end{array}$ \\
\hline 96 & 83 & $\begin{array}{l}\text { Empetrum nigrum L. ssp. hermaphroditum (Hagerup) } \\
\text { Böcher }\end{array}$ & Emni & $\begin{array}{l}\text { Çok Yıllık, } \\
\text { Odunsu, Çalı }\end{array}$ & $6-6$ & & Yeşil & $\begin{array}{l}\text { Mor, } \\
\text { Siyah }\end{array}$ & Orta & $\begin{array}{l}\text { Yayılııı, } \\
\text { Sürünücü }\end{array}$ \\
\hline 97 & 75 & $\begin{array}{l}\text { Polygonum bistorta L. subsp. carneum (Koch) Coode } \\
\text { \& Cullen }\end{array}$ & Pobic & Çok Yıllık, Otsu & $6-8$ & Pembe & Yeşil & & İnce & Dik \\
\hline 98 & 75 & $\begin{array}{l}\text { Geranium ibericum Cav. subsp. jubatum (Hand. } \\
\text { Mazz.) Davis }\end{array}$ & Geibj & Çok Yıllık, Otsu & $7-8$ & $\begin{array}{l}\text { Pembe } \\
\text { Eflatun }\end{array}$ & Yeşil & & Kaba & Dik, Yayılıcı \\
\hline
\end{tabular}




\begin{tabular}{|c|c|c|c|c|c|c|c|c|c|c|}
\hline $\begin{array}{c}\text { Takson } \\
\text { no }\end{array}$ & $\begin{array}{l}\text { Bulunma } \\
\text { oranı (\%) }\end{array}$ & Takson adı & $\begin{array}{l}\text { Kısaltma } \\
\text { lar }\end{array}$ & Yaşam formu & $\begin{array}{l}\text { Çiçeklenme } \\
\text { dönemi }\end{array}$ & Çiçek rengi & Yaprak rengi & $\begin{array}{l}\text { Meyve } \\
\text { rengi }\end{array}$ & Doku & Form \\
\hline 99 & 75 & Scutellaria pontica C. Koch & Scpo & Çok Yıllık, Otsu & $7-8$ & Eflatun & Yeşil & & İnce & Eğik, Yayılıcı \\
\hline 100 & 75 & Arenaria rotundifolia Bieb. subsp. rotundifolia Bieb. & Arro & Çok Yıllık, Otsu & $6-8$ & Beyaz & Yeşil & & İnce & $\begin{array}{l}\text { Eğik, Yayılıcl, } \\
\text { Sürünücü }\end{array}$ \\
\hline 101 & 67 & Polygala alpestris Reichb. & Poalp & Çok Yıllık, Otsu & $4-8$ & Mor, Mavi & Yeşil & & İnce & Eğik, Yayılıcı \\
\hline 102 & 67 & Chaerophyllum astrantiae Boiss. \& Bal. & Chas & Çok Yıllık, Otsu & $8-8$ & Krem & Yeşil & & Orta & Dik \\
\hline 103 & 67 & $\begin{array}{l}\text { Primula elatior (L.) Hill subsp. pseudoelatior (Kusn.) } \\
\text { W. W. Sm. \& Forrest }\end{array}$ & Prielp & Çok Yıllık, Otsu & $6-7$ & Sarı & Yeşil & & Orta & Dik, Rozet \\
\hline 104 & 67 & Potentilla erecta (L.) Rauschel & Poer & Çok Yıllık, Otsu & $4-8$ & Sarı & Yeşil & & Orta & Dik, Yayılıcı \\
\hline 105 & 67 & Hypericum linarioides Bosse. & Hyli & Çok Yıllık, Otsu & $6-8$ & Sarı & Yeşil & & Orta & Dik, Küme \\
\hline 106 & 67 & Alchemilla sericata Reichb. Agg. & Alser & Çok Yıllık, Otsu & $7-9$ & Sarı & Yeşil & & $\begin{array}{l}\text { Orta, } \\
\text { Kaba }\end{array}$ & Eğik, Küme \\
\hline 107 & 67 & Asplenium adiantum-nigrum $\mathrm{L}$. & Asad & Çok Yıllık, Otsu & & & Yeşil & & Orta & Eğik \\
\hline 108 & 67 & Prunella vulgaris $\mathrm{L}$. & Prvu & Çok Yıllık, Otsu & $5-9$ & Eflatun Mor & Yeşil & & Orta & Dik, Yayılıcı \\
\hline 109 & 67 & Polygala supina Schreb. & Posu & $\begin{array}{l}\text { Çok Yillık, Odunsu } \\
\text { Ot }\end{array}$ & $6-7$ & Eflatun Mor & Yeşil & & İnce & $\begin{array}{l}\text { Eğik, } \\
\text { Sürünücü }\end{array}$ \\
\hline 110 & 67 & Coronilla orientalis Miller var. orientalis (All.) Vitman & Cooro & Çok Yıllık, Otsu & $4-7$ & Sarı & Yeşil & & Orta & $\begin{array}{l}\text { Eğik, Yayılıcı, } \\
\text { Küme }\end{array}$ \\
\hline 111 & 67 & Campanula tridentata Schreber & Catr & Çok Yıllık, Otsu & $5-8$ & Mor, Mavi & Yeşil & & Orta & $\begin{array}{l}\text { Dik, Rozet, } \\
\text { Küme }\end{array}$ \\
\hline 112 & 67 & Gypsophila simulatrix Bornm. \& Woron (Endemik) & Gysi & Çok Yıllık, Otsu & $6-7$ & Beyaz & Yeşil & & İnce & $\begin{array}{l}\text { Dik, Yayılıcı, } \\
\text { Küme }\end{array}$ \\
\hline 113 & 67 & Rhamnus microcarpus Boiss. & Rhmi & $\begin{array}{l}\text { Çok Yıllık, } \\
\text { Odunsu, Çalı }\end{array}$ & $5-5$ & & Yeşil & Kırmızı & Orta & $\begin{array}{l}\text { Yatık, } \\
\text { Sürünücü }\end{array}$ \\
\hline 114 & 58 & Carum meifolium (Bieb.) Boiss. & Came & Çok Yıllık, Otsu & $7-8$ & Krem & Yeşil & & İnce & Dik \\
\hline 115 & 58 & Centaurea pulcherrima Willd. var. pulcherrima Willd. & Cechpul & Çok Yıllık, Otsu & $7-8$ & $\begin{array}{l}\text { Eflatun } \\
\text { Pembe }\end{array}$ & Yeşil & & Orta & Dik, Rozet \\
\hline 116 & 58 & Asplenium ruta - muraria L. & Asru & Çok Yıllık & & & Yeşil & & Orta & Eğik, Küme \\
\hline 117 & 58 & Astragalus frickii Bunge & Asfr & Çok Yıllık, Otsu & $6-7$ & Eflatun & Yeşil & & İnce & Eğik, Yayılıcı \\
\hline 118 & 58 & Chamaesciadium acaule (Bieb.) Boiss. & Chac & Çok Yıllık, Otsu & $6-7$ & Sarı & Yeşil & & İnce & $\begin{array}{l}\text { Eğik, Rozet, } \\
\text { Küme }\end{array}$ \\
\hline 119 & 58 & Dryopteris abbreviata (DC.) Newman & Drab & Çok Yıllık, Otsu & & & Yeşil & & Kaba & Dik \\
\hline 120 & 58 & Veronica peduncularis Bieb. & Vepe & Çok Yıllık, Otsu & $4-7$ & Mavi & Yeşil & & İnce & $\begin{array}{l}\text { Eğik, Yayılıcı, } \\
\text { Sürünücü }\end{array}$ \\
\hline 121 & 58 & Pedicularis comosa L. var. sibthorpii (Boiss.) Boiss. & Peco & Çok Yıllık, Otsu & $5-8$ & Sarı & Yeşil & & Orta & Dik \\
\hline 122 & 58 & Gentiana verna L. subsp. pontica (Soltok.) Hayek & Geve & Çok Yıllık, Otsu & $5-7$ & Mavi & Yeşil & & İnce & Dik, Küme \\
\hline 123 & 58 & Dactylorhiza umbrosa (Kar. \& Kir.) Nevski & Daum & $\begin{array}{l}\text { Çok Yillık, Otsu, } \\
\text { Yumrulu }\end{array}$ & $6-7$ & $\begin{array}{l}\text { Eflatun, } \\
\text { Pembe }\end{array}$ & Yeşil & & Orta & Dik \\
\hline
\end{tabular}


Alpin kayalık habitatlardaki doğal bitki taksonlarının bitkisel tasarımlardaki fonksiyonları bakımından değerlendirilmesi

\begin{tabular}{|c|c|c|c|c|c|c|c|c|c|c|}
\hline $\begin{array}{c}\text { Takson } \\
\text { no }\end{array}$ & $\begin{array}{l}\text { Bulunma } \\
\text { oranı (\%) }\end{array}$ & Takson adı & $\begin{array}{l}\text { Kisaltma } \\
\text { lar }\end{array}$ & Yaşam formu & $\begin{array}{l}\text { Çiçeklenme } \\
\text { dönemi }\end{array}$ & Çiçek rengi & Yaprak rengi & $\begin{array}{c}\text { Meyve } \\
\text { rengi }\end{array}$ & Doku & Form \\
\hline 124 & 58 & Potentilla oweriniana Rupr. ex Boiss. & Poow & Çok Yıllık, Otsu & $6-8$ & Pembe & Gri Yeşil & & Orta & $\begin{array}{l}\text { Dik,Kompakt, } \\
\text { Küme }\end{array}$ \\
\hline 125 & 58 & Potentilla doddsii Davis (Endemik) & Podo & Çok Yıllık, Otsu & $7-8$ & Krem & Yeşil & & Kaba & Dik, Yayılıcı \\
\hline 126 & 58 & Hypericum orientale L. & Hyor & Çok Yıllık, Otsu & $5-7$ & Sarı & Yeşil & & Orta & $\begin{array}{l}\text { Dik, Yayılıcı, } \\
\text { Küme }\end{array}$ \\
\hline 127 & 58 & $\begin{array}{l}\text { Asyneuma amplexicaule (Willd.) Hand. Mazz. Subsp. } \\
\text { Amplexicaule (Willd.) Hand. Mazz. Var.amplexicaule } \\
\text { (Willd.) Hand. Mazz. }\end{array}$ & Asam & Çok Yıllık, Otsu & $6-8$ & Mor & Yeşil & & Orta & Dik \\
\hline 128 & 58 & Rhododendron caucasium Pallas & Rhca & $\begin{array}{l}\text { Çok Yıllık, } \\
\text { Odunsu, Çalı }\end{array}$ & $5-7$ & Krem, Beyaz & Yeşil & & Kaba & Yastık, Küme \\
\hline 129 & 50 & Campanula olympica Boiss. & Caol & $\begin{array}{l}\text { İki Yıllık/Çok Yıllık, } \\
\text { Otsu }\end{array}$ & $5-8$ & Mor & Yeşil & & Orta & Dik \\
\hline 130 & 50 & Bromus variegatus Bieb. Subsp variegatus & Brva & Çok Yıllık, Otsu & $6-8$ & & Yeşil & & Orta & Dik \\
\hline 131 & 50 & $\begin{array}{l}\text { Tanacetum coccineum (Willd.) Grierson subsp. } \\
\text { Chamaemelifolium (Somm. \& Lev.) Grierson }\end{array}$ & Taco & Çok Yıllık, Otsu & $6-8$ & Pembe & Yeşil & & Orta & Dik \\
\hline 132 & 50 & $\begin{array}{l}\text { Senecio integrifolius (L.) Clairv. Subsp. Aurantiacus } \\
\text { (Hoppe Ex Willd.) Briq. \& Cavill. Var. Leiocarpus } \\
\text { Boiss. }\end{array}$ & Sein & Çok Yıllık, Otsu & $6-7$ & Sarı & Yeşil & & Orta & Dik \\
\hline 133 & 50 & Draba polytricha Ledeb. & Drpo & Çok Yıllık, Otsu & $4-7$ & Sarı & Yeşil & & İnce & $\begin{array}{l}\text { Dik,Kompakt, } \\
\text { Küme }\end{array}$ \\
\hline 134 & 50 & $\begin{array}{l}\text { Orchis mascula (L.) L. Subsp. Pinetorum (Boiss. \& } \\
\text { Kotschy) G. Camus }\end{array}$ & Ormap & $\begin{array}{l}\text { Çok Yıllık, } \\
\text { Yumrulu }\end{array}$ & $5-6$ & $\begin{array}{l}\text { Pembe } \\
\text { Eflatun }\end{array}$ & Yeşil & & Orta & Dik, Rozet \\
\hline 135 & 50 & $\begin{array}{l}\text { Rosa montana Chaix subsp. Woronowii (Lonacz) Ö. } \\
\text { Nilsson }\end{array}$ & Romo & $\begin{array}{l}\text { Çok Yıllık, } \\
\text { Odunsu, Çalı }\end{array}$ & $6-7$ & $\begin{array}{l}\text { Açık Pembe } \\
\text { Beyaz }\end{array}$ & Yeşil & & Orta & Eğik, Küme \\
\hline 136 & 50 & Aster caucasicus Willd. & Asca & Çok Yıllık, Otsu & $6-8$ & Lila & Yeşil & & İnce & Dik, Rozet \\
\hline 137 & 50 & Fragaria vesca $\mathrm{L}$. & Frve & Çok Yıllık, Otsu & $4-6$ & Beyaz & Yeşil & Kırmızı & İnce & $\begin{array}{l}\text { Eğik, } \\
\text { Sürünücü }\end{array}$ \\
\hline 138 & 42 & Primula veris L. Subsp. Columnae (Ten.) Lüdi & Prvec & Çok Yıllık, Otsu & $4-6$ & Sarı & Yeşil & & Orta & Dik, Rozet \\
\hline 139 & 42 & $\begin{array}{l}\text { Campanula glomerata L. Subsp. Hispida (Witasek) } \\
\text { Hayek }\end{array}$ & Cagl & Çok Yıllık, Otsu & $6-8$ & Mor, Mavi & Yeşil & & Orta & Dik \\
\hline 140 & 42 & Sedum alpestre Vill. & Seal & Çok Yıllık, Otsu & $8-8$ & Sarı & Yeşil & & İnce & $\begin{array}{l}\text { Eğik, } \\
\text { Sürünücü }\end{array}$ \\
\hline 141 & 42 & Rubus idaeus $\mathrm{L}$. & Ruid & $\begin{array}{l}\text { Çok Yıllık, } \\
\text { Odunsu, Çalı }\end{array}$ & 7-7 & Krem & Yeşil & Kırmızı & Kaba & Dik \\
\hline 142 & 42 & Valeriana saxicola C. A. Meyer & Vasa & Çok Yıllık, Otsu & $6-7$ & $\begin{array}{l}\text { Krem, Açık } \\
\text { Pembe }\end{array}$ & Yeşil & & Orta & Dik, Rozet \\
\hline 143 & 42 & Medicago papillosa Boiss. & Mepa & Çok Yıllık, Otsu & $6-8$ & Sarı & Yeşil & & Orta & Eğik, Yayılıcı \\
\hline 144 & 42 & Anthemis melanoloma Trautv. (Endemik) & Anme & Çok Yıllık, Otsu & $7-8$ & Beyaz & Yeşil & & Orta & Dik, Küme \\
\hline
\end{tabular}




\begin{tabular}{|c|c|c|c|c|c|c|c|c|c|c|}
\hline $\begin{array}{c}\text { Takson } \\
\text { no }\end{array}$ & $\begin{array}{l}\text { Bulunma } \\
\text { oranı (\%) }\end{array}$ & Takson adı & $\begin{array}{c}\text { Kısaltma } \\
\text { lar }\end{array}$ & Yaşam formu & $\begin{array}{c}\text { Çiçeklenme } \\
\text { dönemi }\end{array}$ & Çiçek rengi & Yaprak rengi & $\begin{array}{l}\text { Meyve } \\
\text { rengi }\end{array}$ & Doku & Form \\
\hline 145 & 42 & Pimpinella rhodantha Boiss. & Pirh & Çok Yıllık, Otsu & $7-8$ & Pembe & Yeşil & & Orta & Dik \\
\hline 146 & 42 & Alchemilla sp. & Alsp & Çok Yıllık, Otsu & $6-7$ & Sarı & Yeşil & & Orta & Dik, Yayılıcı \\
\hline
\end{tabular}

Scabiosa columbaria L. subsp. columbaria L. var. columbaria L., Trifolium polyphyllum C. A. Meyer, Stachys byzantina C. Koch, Myosotis lithospermifolia (Willd.) Hornem., Alchemilla sericea Willd.,

Euphorbia iberica Boiss., Epilobium angustifolium L., Stachys iberica Bieb. subsp. iberica Bieb. var. iberica Bieb., Geranium ibericum Cav. subsp. ibericum Cav., Briza media L., Luzula sylvatica (Hudson)

Gaudin, Carex pontica Albov, Allium schoenoprasum L., Anemone narcissiflora L. subsp. narcissiflora L., Saxifraga exarata Vill. var. exarata Vill., Myosotis amoena (Rupr.) Boiss., Thalictrum minus L. var. majus (Crantz) Crepin, Carduus adpressus C. A. Meyer, Hypericum bithynicum Boiss., Picea orientalis (L.) Link, Geranium cinereum Cav. subsp. subcaulescens (L'herit. ex DC.) Hayek var. Iazicum

(Woronow) Davis \& Roberts (Endemik), Pedicularis pontica Boiss., Primula auriculata Lam., Valeriana alliariifolia Adams, Centaurea cheiranthifolia Willd. var. cheiranthifolia Willd., Scilla winogradowii Sosn., Geranium psilostemon Ledeb., Cotoneaster nummularia Fisch \& Mey., Sorbus aucuparia L., Rosa pimpinellifolia L., Rhododendron x davisianum R. Milne, Phleum alpinum L., Antennaria dioica (L.)

Gaertner, Saxifraga rotundifoliaL., Muscari coeleste Fomin (Endemik), Gnaphalium stewartii Clarke, Dianthus floribundus Boiss., Rosa villosa L. subsp. mollis (Sm.) Keller \& Gams, Viola sieheana Becker, Pinus sylvestris L., Allium djimilense Boiss. ex Regel (Endemik) 